\title{
USE OF WAIST TO HIP RATIO IN THE DETERMINATION OF THE BODY COMPOSITION IN PRESCHOOL CHILDREN IN LATVIAN POPULATION
}

\author{
Gundega Skruze, Dzintra Kažoka
}

Institute of Anatomy and Anthropology, Rìga Stradin̦š University, Riga, Latvia

\begin{abstract}
According to the World Health Organization (WHO), in 2008, the waist to hip ratio (WHR) has been suggested superior to the body mass index (BMI) in predicting the cardiovascular disease risk in adults and adolescents. There have been studies about the WHR in preschool children in the populations of Pakistan, Chile and Mexico; and it is not the WHO which recommended it as a routine method in preschool children.

The present study includes 85 children ( 41 girls and 44 boys), aged 5 to 7 years, without any chronic conditions. Body height, body weight, waist circumference, hip circumference, triceps skinfold, abdominal skinfold and subscapular skinfold were measured. The WHR, the BMI, the sum of three skinfolds and the percentage of body fat $(\% \mathrm{BF})$ were calculated.

It was found that the WHR decreased with age in girls; there were no specific changes found in the WHR with age in boys. The present study found no correlation in boys or girls between the WHR and the BMI; the WHR and the sum of three skinfolds; the WHR and the percentage of BF. There was also no correlation between the Z-scores of the BMI and Z-scores of the WHR.

Conclusions. The WHR is a questionable body composition marker in preschool children in the Latvian population and must be evaluated separately from other body composition markers.
\end{abstract}

Keywords: Body composition; body mass index; nutrition; waist to hip ratio

\section{INTRODUCTION}

In children, both overweight and underweight are associated with higher morbidity and premature mortality, therefore evaluating the nutrition is an 
important topic in the primary care $[3,17]$. The prevalence of overweight and obesity in children population has risen globally since 1980; however, nearly half of all the deaths in children under 5 all over the world are due to undernutrition $[11,21,22]$.

The most widely used and the WHO recommended anthropometric measurements for determining childhood nutrition are body height, body weight and the BMI [4]. The body's constitution and nutrition can also be evaluated by the use of other anthropometric measurements, like waist circumference (WC), skinfold (SF) thicknesses and body fat percentage (\%BF) $[11,15]$.

According to the World Health Organization (WHO), in 2008, the waist to hip ratio (WHR) has been suggested to be used instead the body mass index (BMI) in predicting the cardiovascular disease risk in adults and adolescents [25]. The WHR is one of the predictors in central obesity in adolescents [18]. There have been studies about the WHR in preschool children in several populations, like Pakistan, Chile and Mexico [13, 14, 24]; and it is not the WHO which recommended it as a routine method in preschool children.

\section{MATERIAL AND METHODS}

The study includes 85 children, aged 5 to 7 years, without any chronic conditions.

Anthropometric measurements. Body height, body weight, waist circumference, hip circumference, triceps SF, abdominal SF and subscapular SF were measured according to standard procedures, using the instruments of "SiberHegner\&Co". Body height was measured using an anthropometer. The weight of the children, wearing minimum clothing and with bare feet, was measured using a portable digital weighing machine. The waist circumference was measured at the level of umbilicus with a flexible measuring tape. The hip circumference was taken around the widest portion of the hips with a flexible measuring tape. The SF measurements were recorded using a SF caliper. All the children were measured in mornings.

Calculations. The BMI was calculated according to the Quetelet formula (1832):

$$
\text { BMI }\left(\mathrm{kg} / \mathrm{m}^{2}\right)=\text { weight }(\mathrm{kg}) / \text { height }\left(\mathrm{m}^{2}\right) \text { [BMI Classification] }
$$

The Waist to hip ratio (WHR) was calculated according to a formula by Bjorntrop, 1987:

WHR $=$ waist circumference $(\mathrm{cm}) /$ hip circumference $(\mathrm{cm})[25]$ 
The sum of three skinfolds was calculated according to the Jackson and Pollock formula (1978):

Three site skinfold $=$ triceps SF $(\mathrm{mm})+\operatorname{abdominal~SF~}(\mathrm{mm})+$ subscapular SF (mm) [9].

The percentage of BF was calculated according to the Slaughter formula (1988):

In boys:

- $\quad$ if (subscapular SF + triceps SF) $=<35 \mathrm{~mm}$ and age $<12$ years:

$$
\% \mathrm{BF}=1.21 \times(\text { subscapular } \mathrm{SF}+\text { triceps } \mathrm{SF})-0.008 \times
$$

$(\text { subscapular } \mathrm{SF}+\text { triceps } \mathrm{SF})^{\wedge} 2-1.7$;

- $\quad$ if (subscapular SF + triceps SF) $>35 \mathrm{~mm}$ :

$$
\% \mathrm{BF}=0.73 \times(\text { subscapular } \mathrm{SF}+\text { triceps } \mathrm{SF})+1.6[19] \text {. }
$$

In girls:

- $\quad$ if (subscapular SF + triceps SF) $=<35 \mathrm{~mm}$ :

$$
\begin{aligned}
\% \mathrm{BF}= & 1.33 \times(\text { subscapular } \mathrm{SF}+\text { triceps } \mathrm{SF})-0.013 \times \\
& (\text { subscapular } \mathrm{SF}+\text { triceps } \mathrm{SF}) \wedge 2-2.5
\end{aligned}
$$

- $\quad$ if (subscapular SF + triceps SF) $>35 \mathrm{~mm}$ :

$\% \mathrm{BF}=0.783 \times($ subscapular SF + triceps SF $)+9.7[19]$.

Data analysis. Data analysis was performed using MS Excel 2007 and IBM SPSS Statistics 21.0 programs. Descriptive statistics and the correlation analysis of several different values were determined gender specifically.

\section{RESULTS}

41 girls and 44 boys were included in the study. The mean age of the girls was 5.95 years ( \pm 0.87 years); of boys 6.14 years ( \pm 0.67 years). One hundred percent of children were urban.

The anthropometric measurements, the BMI, the WHR, the sum of three skinfolds and the percentage of BF are displayed gender specifically in Table 1 and Table 2 .

The waist and hip circumference increased with age in both boys and girls. However, the WHR decreased with age in girls $(\mathrm{p}<0.05)$; there were no specific 
changes found in the WHR with age in boys. There was also no correlation, positive or negative, with the age and the BMI; age and the sum of three skinfolds; and age and the percentage of $\mathrm{BF}$ in either boys or girls.

The BMI and the WHR were expressed as Z-scores, percentile rates and evaluated. The percentile rates of the BMI and the WHR are depicted gender specifically in Table 3 and Table 4.

In girls $68.2 \%$ were in a normal weight range, $14.7 \%$ were underweight, $9.8 \%$ were overweight and $7.3 \%$ were obese. In boys $72.8 \%$ were in a normal weight range, $13.6 \%$ were underweight, $9.1 \%$ were overweight and $4.5 \%$ were obese. In

Table 1. Age-specific subject distribution and descriptive statistics of anthropometric variables among boys

\begin{tabular}{lccc}
\hline Age (years) & $\mathbf{5}$ & $\mathbf{6}$ & $\mathbf{7}$ \\
\hline Number $(\mathrm{n})$ & 7 & 24 & 13 \\
\hline Body weight $(\mathrm{kg})$ & $20.54 \pm 1.67$ & $21.68 \pm 4.54$ & $24.40 \pm 3.85$ \\
\hline Body height $(\mathrm{cm})$ & $113.5 \pm 3.20$ & $117.20 \pm 6.70$ & $123.70 \pm 5.90$ \\
\hline Waist circumference $(\mathrm{cm})$ & $53.23 \pm 2.60$ & $53.14 \pm 4.59$ & $54.16 \pm 6.29$ \\
\hline Hip circumference $(\mathrm{cm})$ & $63.30 \pm 2.46$ & $62.26 \pm 5.88$ & $64.07 \pm 4.36$ \\
\hline BMI $\left(\mathrm{kg} / \mathrm{m}^{2}\right)$ & $15.93 \pm 0.66$ & $15.64 \pm 1.61$ & $15.88 \pm 1.55$ \\
\hline WHR & $0.84 \pm 0.03$ & $0.85 \pm 0.04$ & $0.84 \pm 0.04$ \\
\hline The sum of three skinfolds $(\mathrm{mm})$ & $20.17 \pm 3.71$ & $20.18 \pm 10.27$ & $22.02 \pm 8.71$ \\
\hline The percentage of BF & $13.51 \pm 2.65$ & $13.17 \pm 5.29$ & $14.12 \pm 4.30$ \\
\hline
\end{tabular}

Table 2. Age-specific subject distribution and descriptive statistics of anthropometric variables among girls

\begin{tabular}{lccc}
\hline Age (years) & 5 & 6 & 7 \\
\hline Number $(\mathrm{n})$ & 16 & 11 & 14 \\
\hline Body weight $(\mathrm{kg})$ & $18.86 \pm 2.07$ & $21.93 \pm 2.00$ & $22.81 \pm 4.32$ \\
\hline Body height $(\mathrm{cm})$ & $112.70 \pm 3.50$ & $119.60 \pm 5.30$ & $119.60 \pm 5.30$ \\
\hline Waist circumference $(\mathrm{cm})$ & $51.30 \pm 2.62$ & $52.33 \pm 2.86$ & $53.83 \pm 6.10$ \\
\hline Hip circumference $(\mathrm{cm})$ & $59.93 \pm 4.08$ & $62.37 \pm 3.91$ & $66.30 \pm 5.61$ \\
\hline BMI $\left(\mathrm{kg} / \mathrm{m}^{2}\right)$ & $14.83 \pm 1.36$ & $15.32 \pm 0.78$ & $15.88 \pm 2.30$ \\
\hline WHR & $0.86 \pm 0.04$ & $0.84 \pm 0.03$ & $0.81 \pm 0.04$ \\
\hline The sum of three skinfolds $(\mathrm{mm})$ & $22.94 \pm 6.31$ & $23.31 \pm 5.06$ & $25.73 \pm 10.01$ \\
\hline The percentage of BF & $15.41 \pm 3.97$ & $15.20 \pm 3.07$ & $16.33 \pm 4.47$ \\
\hline
\end{tabular}


Table 3. The BMI and the WHR percentiles in boys

\begin{tabular}{lcc}
\hline Percentile & BMI & WHR \\
\hline 0 to 5.0 & $2(4.5 \%)$ & $2(4.5 \%)$ \\
\hline 5.1 to 15.0 & $4(9.1 \%)$ & $4(9.1 \%)$ \\
\hline 15.1 to 85.0 & $32(72.8 \%)$ & $33(75.1 \%)$ \\
\hline 85.1 to 95.0 & $4(9.1 \%)$ & $3(6.8 \%)$ \\
\hline 95.1 to 100 & $2(4.5 \%)$ & $2(4.5 \%)$ \\
\hline
\end{tabular}

Table 4. The BMI and the WHR percentiles in girls

\begin{tabular}{lcc}
\hline \multicolumn{1}{c}{ Percentile } & BMI & WHR \\
\hline 0 to 5.0 & $2(4.9 \%)$ & $2(4.9 \%)$ \\
\hline 5.1 to 15.0 & $4(9.8 \%)$ & $4(9.8 \%)$ \\
\hline 15.1 to 85.0 & $28(68.2 \%)$ & $30(75.5 \%)$ \\
\hline 85.1 to 95.0 & $4(9.8 \%)$ & $2(4.9 \%)$ \\
\hline 95.1 to 100 & $3(7.3 \%)$ & $2(4.9 \%)$ \\
\hline
\end{tabular}

girls $68.2 \%$ were in between the $15^{\text {th }}$ and $85^{\text {th }}$ percentile of the WHR; in boys it was $75.5 \%$. Under the $15^{\text {th }}$ percentile there were $14.7 \%$ of girls and $13.6 \%$ of boys, but $14.7 \%$ of girls and $11.3 \%$ of boys were over the $85^{\text {th }}$ percentile. The present study analysed the correlations between the WHR and other calculable measurements that determine the body composition in children. There was no correlation found in either boys or girls between the WHR and the BMI; the WHR and the sum of three skinfolds; the WHR and the percentage of BF. There was also no correlation between the Z-scores of the BMI and Z-scores of the WHR, therefore a higher BMI cannot be associated with a higher WHR.

\section{DISCUSSION}

The WC and the hip circumference increased with age in both boys and girls, consistent with previous data [6]. The WC is the simplest clinical measure of childhood central obesity and has been proved a strong predictor of cardiovascular and metabolic disease risk in children because it provides a better estimate of visceral adipose tissue than the BMI and is more efficient than the $\mathrm{BMI}$ in predicting insulin resistance, blood pressure, and serum cholesterol and triglyceride levels [18]. A study by Kolpa et al. (2016) showed that the schoolchildren, aged 10-12 years, with hypertensionm had also a larger hip circumference [10]. The present study did not determine blood pressure in preschool children; therefore it is unknown whether a larger hip circumference can be associated with higher blood pressure in preschool children in the Latvian population.

In the present study the sum of three skinfolds and the percentage of BF showed no statistically significant increase or decrease with age. The sum of three skinfolds contributes negatively to the lean body mass, according to a 
study by Slaughter et al. (1978) [20]. Therefore it is a useful indicator of nutrition in preschool children. The percentage of $\mathrm{BF}$ is a useful metabolic indicator in children [16], and the SF-derived Slaughter formula is highly correlated with the percentage of body fat from dual energy $\mathrm{X}$-ray absorptiometry, which is the most precise method of determining the the percentage of BF [7]. The data of the present study are representative of the sum of three skinfolds and the percentage of BF in preschool children population in Latvia, and can be further used in determining future risks. Calculating the percentage of BF from SF measurements is useful in practice, because the standard $\mathrm{BMI}$ is a weak predictor of the percentage of BF [23]. The SF measurements and the Slaughter formula are not suitable for primary practices due to complicity, however, it may be used in advanced examination or further scientific research in the Latvian population.

In different previous studies, the WHR showed a continuous decrease with advancing age $[1,13]$. The present study shows the same tendency in girls, however, there is no statistically significant decrease in the WHR with age in boys. In a study by Mustaq et al. (2011), the WHR showed a plateau pattern among the boys aged 5-13 years; in girls, the study showed a decrease in the WHR from 9 years of age [14]. Therefore, the present data is credible in showing changes in the WHR in the Latvian preschool children.

Previously published literature suggests the use of pre-specified cut-off points for defining central obesity of WHR $>0.90$ in adult men and $>0.85$ in adult women [5]. In the present study the cut-off of WHR $>0.90$ corresponded at the $88^{\text {th }}$ WHR percentile for boys; the cut-off of $>0.85$ corresponded at the 73rd percentile in girls. These WHR cut-offs used in adults are not suitable to be used as a threshold for obesity in children, consistent to a previous study [1].

The present study found no correlation between the BMI and the WHR in either boys or girls. This contradicts to the results of a study by Zhang et al. (2017) that showed a significantly higher waist-hip ratio in obese children [26]. This can be explained by the fact that the present study only included only a small number of obese children of both genders, therefore a comparison analysis was not performed.

The WHR is used to describe body fat distribution in adults; however, it is influenced by other body factors in children, therefore it is an inconsistent measure of body fat distribution and the risk of obesity related diseases in children [12,13]. A study by Guzman de la Garza et al., 2017, found that the WHR is not significantly correlated with body frame size measures [8]. The 
present study also found no correlation between the WHR and the sum of three skinfolds, and the WHR and the percentage of BF. Therefore, consistent with previous literature data, the body fat distribution and percentage in preschool children should be determined with other anthropometric methods.

According to a study by Vasqez et al. (2017), anthropometric adiposity indicators become associated to cardiometabolic markers only from the age of 7 years, with associations being slightly higher at 10 years [24]. At all ages the $\mathrm{BMI}$ to age, the WC and the waist-to-height ratio correlate with cardiometabolic markers, therefore they are more sensitive in determining cardiometabolic risks, while the WHR is a slightly weaker marker [24]. A study by Qi et al. (2017) in 8 to 16-year-olds found that in boys, the BMI, the WC and the percentage of $\mathrm{BF}$ showed the strongest association with insulin resistance, and was significantly stronger compared with the fat mass index than the WHR; in girls, the percentage of BF showed a significantly stronger association with insulin resistance compared with the BMI, the WC, the WHR [16]. A study by Zhu et al. (2016) found that the BMI correctly identified $77 \%$ of the total dyslipidemic disorders in obese children, aged 7-17, while the WHR identified $70.8 \%$ [27]. This adds to the present study that the WHR should not be used in determining future cardiovascular and metabolic risks in preschool children; it is dubious whether other anthropometric adiposity markers are sensitive in the age of 5-6 years. In preschool children, the WHR is a questionable marker in determining the body composition; however, its use in adolescents and adults is helpful.

The present study had several strengths, for example, the fact that similar studies have not been previously performed in Latvian preschool children; also, the anthropometric measurements were collected by trained health professionals. The data is representative of the modern preschool children's population in Latvia. The disadvantages include low participation and the limited age group.

\section{CONCLUSIONS}

WHR is a questionable body composition marker in preschool children in the Latvian population and must be evaluated separately from other body composition markers. 


\section{REFERENCES}

1. Bacopoulou F., Efthymiou V., Landis G., Rentoumis A., Chrousos G.P. (2015). Waist circumference, waist-to-hip ratio and waist-to-height ratio reference percentiles for abdominal obesity among Greek adolescents. BMC Pediatrics, 15, 50. https://doi.org/10.1186/s12887-015-0366-Z

2. BMI Classification (2006). Global Database on Body Mass Index. World Health Organization. Retrieved 22.04.2017. http://who.int/bmi/index.jsp?introPage=intro_3.html

3. Corsi D.J., Mejía-Guevara I., Subramanian S.V. (2016). Risk factors for chronic undernutrition among children in India: Estimating relative importance, population atributable risk and fractions. Social Science \& Medicine, 157, 165-85. https://doi.org/10.1016/j.socscimed.2015.11.014

4. De Onis M., Onyango A., Borghi E., Siyam A., Blossner M., Lutter C. (2012). Worldwide implementation of the WHO Child Growth Standards. Public Health Nutrition, 2012. https://doi.org/10.1017/S136898001200105X

5. Definition and diagnosis of diabetes mellitus and intermediate hyperglycaemia. World Health Organization. Retrieved 15.06.2017. http://whqlibdoc.who.int/hq/1999/who_ncd_ncs_99.2.pdf

6. Fernandez J.R., Redden D.T., Pietrobelli A., Allison D.B. (2004). Waist circumference percentiles in nationally representative samples of African-American, European-American, and Mexican-American children and adolescents. J Pediatr, 145, 439-44. https://doi.org/10.1016/j.jpeds.2004.06.044

7. Freedman D.S., Ogden C.L., Kit B.K. (2015). Interrelationships between BMI, skinfold thicknesses, percent body fat, and cardiovascular disease risk factors among U.S. children and adolescents. BMC Pediatr, 18, 15, 188. https://doi.org/10.1186/s12887-015-0493-6

8. Guzman de la Garza F.J., Gonzales Ayala A.E., Gomez Nava M., Martinez Monsilvais L.I., Salinas Martinez A.M., Ramirez Lopez E., Mathiew Quiros A., Garcia Quintanilla F. (2017). Body frame size in school children is related to the amount of adipose tissue in different depots but not to adipose distribution. Am J Hum Biol, 2017. https://doi.org/10.1002/ajhb.23014

9. Jackson A.S., Pollock M.L. (1978). Generalized equations for predicting body density of men. British Journal of Nutrition, 40, 3, 497-504. https://doi.org/10.1079/BJN19780152

10. Kolpa M., Jankowicz-Szymanska A., Jurkiewicz B. (2016). High-normal arterial blood pressure in children with excess body weight. Iran J Pediatr, 18; 26 (4), e4677. https://doi.org/10.5812/ijp.4677

11. Kuhle S., Ashley-Martin J., Maguire B., Hamilton, D.C. (2016). Percentile curves for skinfold thickness for Canadian children and youth. PeerJournal, 4, e2247. https://doi.org/10.7717/peerj.2247 
12. Liu A., Hills A.P., Hu X., Du L., Xu Y., Byrne N.M., Ma G. (2010). Waist circumference cut-off values for the prediction of cardiovascular risk factors clustering in Chinese school-aged children: a cross-sectional study. BMC Public Health, 10, 82. https://doi.org/10.1186/1471-2458-10-82

13. Moreno L.A., Fleta J., Mur L., Feja C., Sarria A., Bueno M. (1997). Indices of body fat distribution in Spanish children aged 4.0 to 14.9 years. Journal of Pediatric Gastroenterology \& Nutrition, 25, 2, 175-81. https://doi.org/10.1097/00005176-199708000-00008

14. Mushtaq M.U., Gull S., Abdullah H.M., Shahid U., Shad M.A., Akram J. (2011). Waist circumference, waist-hip ratio and waist-height ratio percentiles and central obesity among Pakistani children aged five to twelve years. BMC Pediatrics, 11, 105. https://doi.org/10.1186/1471-2431-11-105

15. Ochiai H., Shirasawa T., Nishimura R., Morimoto A., Shimada N., Ohtsu T., Kujirai E., Hoshino H., Tajima N., Kokaze A. (2010). Relationship of body mass index to percent body fat and waist circumference among schoolchildren in Japan - the influence of gender and obesity: a population-based cross-sectional study. BMC Public Health, 10, 493. https://doi.org/10.1186/1471-2458-10-493

16. Qibin Q., Hua S., Perreira K.M., Cai J., Van Horn L., Schneiderman N., Thyagarajan B., Delameter A.M., Kaplan R.C., Isasi C.R. (2017). Sex Differences in Associations of Adiposity Measures and Insulin Resistance in US Hispanic/ Latino Youth: The Hispanic Community Children's Health Study/Study of Latino Youth (SOL Youth). J Clin Endocrinol Metab, 102, 1, 185-94. https://doi.org/10.1210/jc.2016-2279

17. Reilly J.J., Kelly J. (2011). Long-term impact of overweight and obesity in childhood and adolescence on morbidity and premature mortality in adulthood: systematic review. International Journal of Obesity, 35, 891-898. https://doi.org/10.1038/ijo.2010.222

18. Savva S.C., Tornaritis M., Savva M.E. (2000). Waist circumference and waistto-height ratio are better predictors of cardiovascular disease risk factors in children than body mass index. Int J Obes Relat Metab Disord, 24, 1453-58. https://doi.org/10.1038/sj.ijo.0801401

19. Slaughter M.H., Lohman T.G., Boileau R.A., Horswill C.A., Stillman R.J., Van Loan M.D., Bemben D.A. (1988). Skinfold equations for estimation of body fatness in children and youth. American Journal of Human Biology, 60, 5, 709-723.

20. Slaughter M.H., Lohman T.G., Boileau R.A. (1978). Relationship of anthropometric dimensions to lean body mass. Ann Human Biol, 5, 5, 469-82. https://doi.org/10.1080/03014467800003121

21. Stevens G.A., Singh G.M., Lu Y., Danaei G., Lin J.K., Finucane M.M., Bahalm A.N., McIntire R.K., Gutierrz H.R., Cown M., Paciorek C.J., Farzadfar F., Riley L., Ezzati M. (2012). National, regional, and global trends in adult 
overweight and obesity prevalences. Population Health Metrics, 10, 22. https://doi.org/10.1186/1478-7954-10-22

22. UNICEF Data: Monitoring the Situation of Children and Women (2017). Retrieved 01.05.2017. https://data.unicef.org/topic/nutrition/malnutrition/

23. Vanderwall C., Randall Clark R., Eickhoff J., Carrel A.L. (2017). BMI is a poor predictor of adiposity in young overweight and obese children. BMC Pediatr, 17, 1, 135. https://doi.org/10.1186/s12887-017-0891-z

24. Vasquez F.D., Corvalan C.L., Uauy R.E., Kain J.A. (2017). Anthropometric indicators as predictors of total body fat and cardiometabolic risk factors in Chilean children at 4, 7 and 10 years of age. European Journal of Clinical Nutrition, 71, 536-43. https://doi.org/10.1038/ejcn.2016.213

25. Waist Circumference and Waist-Hip Ratio (2008). Report of a WHO Expert Consultation Geneva, 8-11 December 2008. Retrieved 15.06.2017. http://apps.who.int/iris/bitstream/10665/44583/1/9789241501491_eng.pdf

26. Zhang M.I., Li F., Wang J.P. (2017). Correlation analysis of serum obestatin expression with insulin resistance in childhood obesity. Genet Mol Res 28;16, 2. https://doi.org/10.4238/gmr16029210

27. Zhu Y., Shao Z., Jing J., Ma J., Chen Y., Li X., Yang W., Guo L., Jin Y. (2016). Body mass index is better than other anthropometric indices for identifying dyslipidemia in Chinese children with obesity. PloS One, 10; 11, 3, e0149392. https://doi.org/10.1371/journal.pone.0149392

\section{Address for correspondence}

Gundega Skruze

Rīga Stradiņš University, Institute of Anatomy and Anthropology

Kronvalda blv. 9, Riga, Latvia, LV-1010

E-mail: gundega.skruze@gmail.com

Tel. +371 67061551; +37129855933 